УДК $327(73+520: 5: 265)$

https://doi.org/10.24866/1813-3274/2021-1/70-83

Ф. Г. Демчук ${ }^{1}$, Национальный исследовательский университет «Высшая школа экономики», г. Санкт-Петербург; Санкт-Петербургский государственный университет, г. Санкт-Петербург, Россия E-mail: fstrugach@hse.ru

\title{
ТРАМП И ЯПОНИЯ: НОВЫЙ ТИХООКЕАНСКИЙ ПОВОРОТ? ИТОГИ ПОЛИТИКИ ДОНАЛЬДА ТРАМПА В ЯПОНИИ
}

Аннотация. Исследователи до сих пор оценивают итоги Тихоокеанской стратегии Барака Обамы. Несмотря на осторожность, скрупулезность в принятии решений и глубокую экспертную проработку, многие решения президента Обамы оказались спорными и вызывали нарекания со стороны различных игроков в регионе, включая традиционного союзника - Японию. Политика его преемника на должности президента США Дональда Трампа оказалась более удачной во многих аспектах. Трампу удалось укрепить отношения с Японией и достичь глубокого двустороннего взаимодействия во многих сферах. При этом он подписал указ о выходе США из Транстихоокеанского партнёрства, что в итоге привело к положительному результату для Токио, Япония вернула себе статус самостоятельного игрока и лидера в АТР.

Ключевые слова: США, Япония, АТР, Барак Обама, отношения США и Японии, Синдзо Абэ, Дональд Трамп, Тихоокеанский поворот, Транстихоокеанское партнёрство.

${ }^{1}$ Демчук Фаина Геннадьевна, преподаватель Департамента востоковедения и африканистики, Национальный исследовательский университет «Высшая школа экономики», г. Санкт-Петербург; аспирант кафедры американских исследований, Санкт-Петербургский государственный университет, г. Санкт-Петербург, Россия.

Для циитирования: Демчук Ф. Г. Трамп и Япония: новый тихоокеанский поворот? Итоги политики Д. Трампа в Японии // Азиатско-Тихоокеанский регион: экономика, политика и право. 2021. № 1. С. 70-83. https://doi.org/10.24866/1813-3274/2021-1/70-83.

(C) Демчук Ф. Г., 2021 
Faina G. Demchuk ${ }^{1}$, National Research University Higher School of Economics;

St. Petersburg State University, St. Petersburg, Russia

E-mail: fstrugach@hse.ru

\section{TRUMP AND JAPAN: A NEW PACIFIC TWIST? RESULTS OF DONALD TRUMP'S POLICY IN JAPAN}

Abstract. Researchers are still assessing the outcome of Barack Obama's Pacific strategy. Despite caution, scrupulousness in decision-making and deep expert study, many of President Obama's decisions were controversial and provoked criticism from various players in the region, including Japan, a traditional ally of the USA. The policies of his successor, President Donald Trump, have been more successful in many ways. President Trump managed to strengthen relations with Japan and achieve deep bilateral interaction in many areas, which affects the positions of the United States and China and, most importantly, allows Japan to regain its status as an independent player and leader in the APR.

Key words: USA, Japan, Asia-Pacific, Barack Obama, relations between the USA and Japan, Shinzo Abe, Donald Trump, Pacific turn, Trans-Pacific Partnership.

В ноябре 2020 г. в США состоялись очередные выборы президента, которые определили, что в 2021 г. к власти придёт кандидат от Демократической партии Джо Байден. И сейчас уже можно подводить некоторые итоги внешней политики, которую президент Дональд Трамп успел провести за четыре года. Многие решения, принятые Трампом, называют импульсивными и непоследовательными, не все из них привели к успешным результатам для США на мировой арене. Тем не менее, некоторые аспекты внешнеполитической стратегии Вашингтона всё же можно назвать удачными.

В настоящее время одним из самых перспективных направлений внешней политики США является Азиатско-Тихоокеанский регион, что было заложено ещё президентом Бараком Обамой в рамках его стратегии поворота к Азии. Однако Тихоокеанский поворот Обамы многие исследователи оценивают неоднозначно. В частности, напряжёнными были и отношения с ближайшим партнёром США в

${ }^{1}$ Faina G. Demchuk, Lecturer, Department of Oriental and African Studies, National Research University Higher School of Economics; Postgraduate Student, Department of American Studies, St. Petersburg State University, St. Petersburg, Russia.

For citing: Demchuk F. G. Trump and Japan: A New Pacific Twist? Results of Donald Trump's policy in Japan // PACIFIC RIM: Economics, Politics, Law. 2021. No. 1. C. 70-83. https://doi.org/10.24866/18133274/2021-1/70-83. 
регионе - с Японией. Кажется, что Трампу удалось установить более стабильные отношения с Токио, но так ли это на самом деле?

Цель данной статьи - провести параллель между Тихоокеанской политикой Барака Обамы и Дональда Трампа и определить, насколько успешной оказалась политика последнего по отношению к Японии.

Несмотря на актуальность данной темы для понимания расстановки политических сил в АТР данная тема затрагивалась фрагментарно, без учёта анализа позиции политического истеблишмента Японии и влияния личности президента Д. Трампа на двухсторонние отношения с Токио [1; 2].

Источниками для исследования послужили документы и экспертные отчёты правительства США и Японии, а также официальные заявления и договоры двух стран. Методы исследования включают в себя документальный анализ, сравнительный анализ, а также системный анализ, что позволяет рассматривать дальневосточную политику США в АТР и двусторонние отношения межу США и Японией в контексте международной обстановки и в рамках национальных интересов Вашингтона и Токио.

Статья состоит из двух разделов. В первом разделе анализируется наследие президента Б. Обамы в дальневосточной политике США. Во втором разделе - результаты политики Д. Трампа в сравнении с политикой предшествующей администрации.

\section{Тихоокеанский поворот Барака Обамы}

Одним из важных элементов новой внешнеполитической стратегии администрации Барака Обамы был курс на поворот в сторону Азии, или Тихоокеанский поворот (Pivot to Asia). Эта стратегия, впервые провозглашенная госсекретарем Хилари Клинтон в 2011 г., подразумевала широкое вовлечение США в регион, тесное сотрудничество со старыми партнёрами и налаживание связей - с новыми.

Можно назвать несколько причин, по которым Соединенные Штаты решили переориентировать своё внимание на Тихоокеанский регион. Вашингтон беспокоило всё возрастающее влияние Китая не только в регионе, но и на всей мировой арене [3]. Кроме того, США пытались продемонстрировать себя в качестве мирового лидера после неудачных действий на Ближнем Востоке [4]. Наконец, личные пристрастия президента к региону, в котором он провёл часть своего детства, также выступали причиной активизации контактов.

Тем не менее, несмотря на обширные планы Соединенных Штатов в рамках новой политики, не все проекты удалось осуществить, а отношения с ближайшим партнёром в регионе - Японией - нельзя назвать самыми удачными.

На первый срок администрации Б. Обамы (2009-2013 гг.) пришлась политическая нестабильность внутри Японии. На смену Либерально-демократической партии (ЛДПЯ), которая была у власти 54 года подряд, пришла Демократическая пар- 
тия (ДПЯ) во главе с премьер-министром Юкио Хатояма. США со своей стороны были настроены на диалог с Токио, но японское правительство решило переориентироваться на Китай и отойти от американской зависимости [5, р. 729]. Новая власть Японии всячески демонстрировала этот новый и неожиданный поворот тем, что отменяла встречи с представителями США и вела себя в целом холодно, что заставило Вашингтон усомниться в своем азиатском партнёре [6]. После смены нескольких премьер-министров из ДПЯ в 2012 г. к власти наконец снова пришла ЛДПЯ во главе с Синдзо Абэ. Однако и при такой более стабильной ситуации в Токио, а также в целом проамериканской направленности ЛДПЯ нельзя было сказать, что в отношениях между Японией и США всё вернулось к традиционным, особым отношениям между США и Японией.

Одной из главных проблем оказались натянутые личные отношения лидеров двух стран - Барака Обамы и Синдзо Абэ [7; 8]. Для либерального американского президента взгляды Абэ были слишком консервативными и даже в какой-то степени националистическими. Например, лидер США был недоволен ситуацией вокруг храма Ясукуни - это синтоистский храм в Токио, который является местом захоронения военных преступников Второй мировой войны и символом японского милитаризма первой половины XX века. Вопрос о посещении храма официальными представителями власти Японии волновал Китай и Южную Корею - страны, наиболее пострадавшие от японской агрессии во время Второй мировой войны. Однако посещение храма премьер-министром Абэ в декабре 2013 г. вызвало недовольство американской стороны, так как это совершенно не соответствовало той роли, которую должна была выполнять Япония, по мнению США [9].

Портила отношения между странами и ситуация вокруг России. Дело в том, что как раз в 2013-2014 гг. разгорался конфликт вокруг Украины, и в связи с этим США и многие другие страны присоединились к санкциям против России, однако отношения Абэ и Владимира Путина оставались довольно близкими.

Следующим сложным моментом в японо-американских отношениях стал первый визит Барака Обамы в Японию при власти Синдзо Абэ. Предыдущие месяцы перед азиатским турне, которое было запланировано на апрель 2014 г., были наполнены официальными недовольствами и осуждениями с обеих сторон. Возможно поэтому изначально президент США вообще не планировал заезжать в Токио, что вызвало беспокойство японской стороны. Япония настаивала на том, чтобы Обама всё же посетил страну, что, по мнению японских властей, должно было продемонстрировать стабильность двусторонних отношений и признание Японии как лидера в АТР. Однако сам факт того, что эту стабильность надо было подтверждать саммитом, уже говорил о проблемах в отношениях [10].

Безусловно, страны всё же тесно сотрудничали в области экономики и безопасности. Например, в результате долгих переговоров американская сторона 
смогла добиться от Японии согласия на вступление в Транстихоокеанское партнёрство (ТТП). Такая инициатива Обамы по заключению соглашения с одиннадцатью крупнейшими экономиками Тихоокеанского региона, за исключением КНР, преследовала несколько целей. Во-первых, США надеялись укрепить свои экономические позиции в АТР, составить конкуренцию Китаю и создать вокруг него кольцо дружественных Вашингтону стран [11, р. 50]. Во-вторых, между Японией и США на тот момент так и не было заключено торгового соглашения, без которого страны не могли договориться о снижении тарифов и увеличении товарооборота. Вступление Японии в ТТП могло бы решить эту проблему.

Достигнуты были и определённые успехи в области безопасности. В частности, важным шагом стало публичное заявление Обамы, в котором он поддерживал Токио в споре за острова Сэнкаку (Дяоюйдао) [12]. Принадлежность на эти острова оспаривают Япония и КНР уже многие годы. Конфликт особенно обострился в 2012-2013 гг., и речь президента США подчёркивала, что американская сторона готова придерживаться своих обязательств в плане защиты японской территории.

Можно утверждать, что отношения США и Японии продвинулись вперёд во многих аспектах, но некоторые исследователи считают, что политика Обамы в рамках Тихоокеанского поворота была не во всём удачной, в том числе и в плане двусторонних отношений с Японией [13]. Например, вместо ребалансировки внешней политики Вашингтон стал незаслуженно уделять гораздо меньше внимания таким регионам, как Ближний Восток и Европа, а военное усиление в АТР, которое не было необходимо в таком объёме, привело к более агрессивной политике Китая.

\section{Новый поворот?}

Сначала казалось, что будущий президент США Дональд Трамп не будет выстраивать близкие отношения с Японией. Во время своей предвыборной кампании он неоднократно утверждал, что видит в Токио одного из главных соперников и угрозу американской экономике. В некоторых выступлениях он даже утверждал, что стоит отменить договор о безопасности между двумя странами [14].

Одним из первых решений на посту президента Трамп выполнил своё предвыборное обещание - подписал указ о выходе из ТТП, поскольку он утверждал, что открытая экономика может нанести ущерб американским производителям [15]. Это решение не стало неожиданностью для японской стороны, потому что Токио внимательно следил за предвыборной гонкой в США и готов был выстраивать отношения с любым президентом.

Несмотря на негативные заявления Трампа в отношении Японии, двусторонние отношения начались благоприятно, что во многом является заслугой премьерминистра Абэ. Сразу же после оглашения результатов президентских выборов в ноябре 2016 г. Абэ решил нанести визит будущему лидеру США. Поскольку инау- 
гурация Трампа ещё не прошла, то этот визит носил неофициальный характер. Однако и Абэ, и Трамп высказались в очень тёплом ключе об этой встрече и подтвердили дружеские отношения с перспективой развития их в будущем [16, с. 205].

Если сравнивать японское направление внешней политики Обамы и Трампа, то одним из самых заметных отличий является сфера личных отношений. Если, как говорилось выше, Обама не смог найти общего языка с Абэ, а консервативные взгляды последнего не нравились демократической партии США, то с Трампом японскому премьер-министру удалось создать исключительно хорошие отношения.

На начало 2020 г. количество личных встреч и телефонных разговоров между двумя лидерами близилось к 50 [17]. Это совершенно беспрецедентная цифра для японо-американских отношений. Абэ и Трамп создавали в СМИ образ не только коллег, но и друзей, которые вместе играют в гольф и ходят обедать. Некоторые исследователи считают, что японский премьер-министр использовал такой личный подход, чтобы продемонстрировать Трампу преимущества партнёрства с Токио [17]. Но даже если это и был тщательно проработанный план Абэ, то всё же у двух лидеров наблюдаются схожие консервативные взгляды и ценности и общее видение внешнеполитической стратегии, что позволяет им поддерживать в действительности тесные отношения.

Общие взгляды на мировую политику привели к более тесному сотрудничеству двух стран в области безопасности. В частности, администрация Трампа поддержала две инициативы, в разное время предложенные японским премьерминистром. Одна из них - концепция Индо-Тихоокеанского региона или Free and Open Indo-Pacific (Свободный и открытый Индо-Тихоокеанский регион). Формально эта стратегия была впервые провозглашена премьер-министром Абэ в августе 2016 г. как сеть, объединяющая страны и региональные организации, которые считают своим приоритетом свободу, открытую экономику, мир и процветание [18].

Подход к этой стратегии изменился, когда США заинтересовались идеями Абэ. Вашингтон решил использовать стратегию, предложенную японским премьерминистром, как инструмент сдерживания экономического роста КНР и как альтернативу китайской стратегии «Один пояс и один путь» (Belt and Road Initiative) [19]. Если говорить о причинах, по которым Япония изначально сформировала данную стратегию, то помимо очевидных, таких как более глубокое торговое сотрудничество со странами региона и продвижение своих экономических интересов, можно назвать китайскую угрозу [20]. Однако в отличие от США японская сторона не говорила об этом так прямо и открыто.

В дальнейшем стратегия была подкреплена совместным заявлением двух государств в ноябре 2018 г. [21]. В нём перечислялись конкретные меры, которые США и Япония собираются исполнять в рамках новой стратегии «Свободного и открыто- 
го Индо-Тихоокеанского региона». Среди них - развитие энергетической сферы и сотрудничество в рамках специально созданного энергетического партнёрства США и Японии (Japan-US Strategic Energy Partnership), стимулирование японскими и американскими финансовыми организациями экономического развития в регионе, а также взаимодействие на уровне частного сектора.

Кроме того, США и Япония рассматривают эту стратегию как возможность для сотрудничества в области безопасности. В рамках стратегии ведётся четырёхсторонний диалог по безопасности, который помимо Японии и США включает в себя Индию и Австралию (Quadrilateral Security Dialogue/QSD). Необходимо отметить, что инициатива была предложена Синдзо Абэ еще в 2007 г., но не получила никакого развития или поддержки. Теперь, благодаря более тесному сотрудничеству Вашингтона и Токио, этот диалог вновь был возобновлен. Представители стран встретились для совещаний по этому вопросу пять раз в период с 2017 г. по 2019 г. Кроме того, Трамп впервые в официальной речи подчеркнул важность этого четырёхстороннего диалога во время встречи с премьер-министром Индии Н. Д. Моди в феврале 2020 г. [22]. Понятно, что эта инициатива, как и экономическая составляющая стратегии, нацелена на сдерживание Китая в регионе [19]. Однако никаких конкретных шагов в области безопасности не было предпринято, но ведётся активное обсуждение всеми четырьмя участниками.

Выход США из соглашения ТТП не стал таким ударом для Японии, как могло показаться сначала. Некоторые исследователи склоняются к мнению, что Абэ так поспешил с уже упомянутым выше визитом к ещё не вступившему в должность Трампу как раз для того, чтобы обсудить выход США из ТТП [23]. Дело в том, что обсуждение вступления Японии в это соглашение продолжалось не один год, а без Вашингтона Транстихоокеанское партнёрство сложно было представить, поэтому Абэ не хотелось, чтобы все эти переговоры прошли впустую. Возможность вновь вернуться в ТТП обсуждалась в Токио и после вступления Трампа в должность, но президент США был непреклонен.

Тем не менее такой поворот событий неожиданно привёл к позитивным последствиям для Японии, а точнее для становления Японии как самостоятельного и сильного игрока в АТР. Взяв на себя лидерскую роль, именно Абэ стал инициатором нового формата ТТП без США. Невозможно точно сказать, чем руководствовался премьер-министр Японии - возможно его испугало желание Латиноамериканских стран пригласить КНР в ТТП, ведь Китай рассматривается как один из основных экономических соперников Токио на мировой арене. Кроме того, возможно руководство Японии увидело в этом партнёрстве выгоду: дело в том, что после ухода США именно Япония оказалась самой экономически развитой страной и могла не только получить наибольшую выгоду из этого соглашения в экономическом плане, но диктовать свои условия и выстроить ТТП вокруг своих интересов 
[24, с. 184]. В итоге, благодаря активной деятельности Абэ [23], в мае 2017 г. во Вьетнаме состоялась вторая встреча одиннадцати стран, где их представители окончательно согласились продвигать партнёрство дальше даже без США.

Относительно успешно урегулировать экономические отношения между США и Японией удалось и без ТТП, в формате двустороннего договора. Вопрос о переговорах по поводу этого договора был отложен до сентября 2018 г., потому что Вашингтон был занят обсуждением тарифных ставок с Китаем и торгового соглашения с Евросоюзом. В сентябре Трамп и Абэ встретились в Нью-Йорке, после чего выпустили не очень конкретизированное совместное заявление о том, что страны в ближайшем будущем собираются вступить в переговоры о двустороннем соглашении и что в данном соглашении должны быть обязательно учтены вопросы автомобильной индустрии и сельского хозяйства [25].

В итоге официальное начало переговорам было положено только в апреле 2019 г. После многочисленных раундов совещаний, а также после обсуждения данных вопросов на высшем уровне во время встречи большой двадцатки в Осаке (Япония) в мае 2019 г. страны всё-таки смогли договориться по основным вопросам. Согласно новому соглашению [26], подписанному 7 октября 2019 г., Япония снизила тарифы на американскую сельскохозяйственную продукцию, что было очень важным моментом для Трампа, который назвал это победой для американских фермеров [27]. Кроме того, соглашение затрагивает вопросы цифровой торговли.

Однако для Японии данное соглашение пока не настолько выгодно как для США, поскольку пошлина на японские автомобили осталась неизменной, хотя Америка всё же снизила тарифы на импорт некоторых промышленных товаров. Соглашение рассматривается как первый этап урегулирования торговых вопросов между США и Японией, поэтому возможно, что в будущем многие незатронутые вопросы также будут согласованы.

Интересен также вопрос, о том, что именно привело к такому повороту США в сторону Японии. Некоторые пояснения даёт бывший советник по национальной безопасности Джон Болтон, который подал в отставку из-за разногласий с Трампом и госсекретарем Майком Помпео на политику по отношению к Ирану, КНДР и другим странам в сентябре 2019 г. В своих нашумевших мемуарах - «Комната, где это происходило» [28] - он объясняет поворот Трампа в сторону Японии из-за того, что самые близкие отношения среди всех мировых лидеров у президента были именно с Синдзо Абэ [28, p. 312], что подтверждается множеством личных встреч, схожими взглядами на стратегию по отношению к Северной Корее и Китаю.

Личные качества президента оказали влияние на формирование новых отношений с Японией. В своих мемуарах Болтон создает образ Трампа как импульсивного человека, который не обдумывает свои действия и не учитывает рекомендации своих советников и помощников. Он пишет, что президент принимает решения, 
«основываясь на инстинктах, полагаясь на личные отношения с мировыми лидерами и мастерство ведущего шоу на телевидении» [28, р. 7]. Кроме того, автор утверждает, что вся политика президента ориентирована на выборы в 2020 г., а главной целью всех его решений была личная выгода и попытка заработать как можно больше голосов избирателей [28, p. 437].

В любом случае, Трамп в отличие от Обамы, который широко пользовался рекомендациями аналитических центров и советников, принимал свои решения совершенно иным образом. Возможно для него были важны прежде всего личные отношения с лидером той или иной страны. Премьер-министру Абэ удалось найти подход к этому президенту США и успешно использовать такой тесный контакт с ним для продвижения интересов Японии [29].

\section{Заключение}

Какими бы ни были истинные мотивы Трампа - желание личной экономической выгоды, создание союза против Китая или получение большей поддержки избирателей и бизнес-сообщества, но его политика по отношению к Японии привела к тесному двустороннему сотрудничеству во многих сферах. В отличие от его предшественника, президенту США Дональду Трампу удавалось проводить более успешную, эффективную и сбалансированную дальневосточную политику. Даже, казалось бы, негативные стороны, такие как выход США из ТТП, в итоге привели к положительному результату для Токио. Япония получила более самостоятельную и лидерскую роль на мировой арене.

В отличие от продуманной и осмысленной стратегии Тихоокеанского поворота администрации Обамы, Трамп действовал импульсивно, хаотично, но результаты такой политики по отношению к Японии приносят хорошие результаты для обеих стран. Несмотря на некоторые спорные моменты (например, вопрос об американских базах на территории Японии и плате за их содержание), двусторонние отношения между странами продвинулись на новый уровень и по многим параметрам они сейчас более крепкие, чем когда-либо.

Глубокая вовлечённость США в регион и в вопросы, связанные с Токио, сотрудничество двух стран в сфере экономики и безопасности, близкие и доверительные отношения, которые складывались ещё недавно между Трампом и Абэ, говорят о том, что возможно между США и Японией наступил новый этап Тихоокеанского поворота в регионе, в котором Токио отведена роль лидера.

В настоящее время Абэ ушёл в отставку, а Трампа в 2021 г. сменил кандидат от Демократической партии Джо Байден. Пока сложно утверждать, как именно будут выстраивать отношения новые лидеры двух стран, но можно точно сказать, что за прошедшие четыре года премьер-министр Японии и президент США заложили основу для дальнейшего укрепления отношений. 


\section{Список литературы}

1. Торкунов, А. Стратегия администрации Трампа в Азиатско-Тихоокеанском регионе // Мировая экономика и международные отношения. - 2019. - № 6. - С. 25-37.

2. Яковлев, П. «Фактор Трампа» и меняющийся облик глобализации // Мировая экономика и международные отношения. - 2017. - № 7. - С. 5-14.

3. Schoff, J. L. Uncommon alliance for the common good: the United States and Japan after the cold war / J. L. Schoff. - Washington, DC : Carnegie Endowment for International Peace Publications Department, 2017. - 272 p.

4. Kelly, R. Obama's legacy: leaving Northeast Asia on a high point // The Interpreter. - 2017. - 17 January. - URL: https://www.lowyinstitute.org/the-interpreter/obamaslegacy-leaving-northeast-asia-high-point (дата обращения: 12.01.2020).

5. Garver, J. W. China's quest: the history of the foreign relations of the People's Republic, revised and updated / J. W. Garver. - Oxford : Oxford University Press, 2016. -888 p.

6. Pomfret, J. U.S. Concerned about New Japanese Premier Hatoyama // Washington Post. - URL: https:/www.washingtonpost.com/wp-dyn/content/article/2009/12/28 /AR2009122802271.html?hpid\%3Dtopnews\&sub=AR (дата обращения: 11.01.2020).

7. Goldberg, J. How Obama views the men and women who (also) rule the world // The Atlantic. - URL: https://www.theatlantic.com/international/archive/2016/03/obamagoldberg-world-leaders/473367/ (дата обращения: 12.01.2020).

8. Abiru, R. Abe and Obama: a Long Road // Japan Forward. - URL: https://japanforward.com/abe-and-obama-a-long-road/ (дата обращения: 13.01.2020).

9. Chen Yo-Jung. US-Japan Relations and Obama's Visit to Japan // The Diplomat. - URL: https://thediplomat.com/2014/04/us-japan-relations-and-obamas-visit-tojapan/ (дата обращения: 12.01.2020).

10. McGregor, R. Asia's reckoning: the struggle for global dominance / R. McGregor. - [S. 1.] : Penguin books, 2017. -320 p.

11. Backer, L. C. The Trans-Pacific partnership: Japan, China, the U.S., and the emerging shape of a new world trade regulatory order // Washington University Global Studies Law Review. - 2014. - Vol. 12, iss. 1. - URL: https://openscholarship.wus t1.edu/law_globalstudies/vol13/iss1/6/ (дата обращения: 12.01.2020).

12. Joint press conference with President Obama and Prime Minister Abe of Japan // The White House, President Barack Obama. - URL: https://obamawhitehouse.archiv es.gov/the-press-office/2014/04/24/joint-press-conference-president-obama-and-primeminister-abe-japan (дата обращения: 13.01.2020).

13. Ford, J. The pivot to Asia was Obama's biggest mistake // The Diplomat. URL: https://thediplomat.com/2017/01/the-pivot-to-asia-was-obamas-biggest-mistake/ (дата обращения: 20.05.2020). 
14. Hunt, J. Japan's Pivot from Obama to Trump // The New Yorker. - 2016. No. 6. - URL: https://www.newyorker.com/news/news-desk/japans-pivot-from-obamato-trump (дата обращения: 15.02.2020).

15. Lobosco, K. Trump pulled out of a massive trade deal. Now 11 countries are going ahead without the US. December 30, 2018 // CNN. - URL: https://edition.cnn.com/2018/12/29/politics/tpp-trade-trump/index.html (дата обращения: 16.02.2020).

16. トランプ政権と日本 - NHK取材班 東京、2017年 - Политика Трампа в Японии. - Токио : NHK, 2017. - $231 \mathrm{c}$.

17. Smith, S. A. Forty-two and counting... The Trump-Abe connection// Council on Foreign Affairs. - URL: https://www.cfr.org/blog/forty-two-and-countingthe-trumpabe-connection (дата обращения: 12.05.2020).

18. Address by Prime Minister Shinzo Abe at the Opening Session of the Sixth Tokyo International Conference on African development (TICAD VI) // Ministry of Foreign Affairs of Japan. - URL: https://www.mofa.go.jp/afr/af2/page4e_000496.html (дата обращения: 21.02.2020).

19. Mehta, S. The free and open Indo-Pacific strategy: a way forward // Asia and the Pacific Policy Society. - URL: https://www.policyforum.net/the-free-and-open-indopacific-strategy-a-way-forward/ (дата обращения: 23.02.2020).

20. Szechenyi, N. Working Toward Free and Open Indo-Pacific / N. Szechenyi, Y. Hosoya // Carnegie Endowment for International Peace. - URL: https://carnegieendo wment.org/2019/10/10/working-toward-free-and-open-indo-pacific-pub-80023 (дата обращения: 12.02.2020).

21. U.S.-Japan joint statement on advancing a free and open Indo-Pacific through energy, infrastructure and digital connectivity cooperation // The White House. - URL: https://www.whitehouse.gov/briefings-statements/u-s-japan-joint-statement-advancing-freeopen-indo-pacific-energy-infrastructure-digital-connectivity-cooperation/ (дата обращения: 18.02.2020).

22. US President Donald Trump announces revival of QUAD, says working with Pakistan to counter terrorism // Hindustanian Times. - URL: https:/www.hindustanti mes.com/india-news/us-president-donald-trump-announces-revival-of-quad-says-working-withpakistan-to-counter-terrorism/story-ZF3R5YRF54a0yJvIKPF6QM.html (дата обращения: 18.01.2020).

23. Terada, T. How and why Japan has saved the TPP: From Trump Tower to Davos // The Asan Forum. - URL: http://www.theasanforum.org/how-and-why-japan-hassaved-the-tpp-from-trump-tower-to-davos/ (дата обращения: 17.02.2020).

24. 藤井厳喜。日米刘等。トランプ(変わる日本の国防・外交・経斎。東京 2017 . Фуджи, Г. Союз Японии и США. Национальная оборона, дипломатия и экономика Японии меняются с Трампом / Г. Фуджи. - Токио, 2017. - 208 с. 
25. Joint Statements of the United States and Japan // The White House. - URL: https://www.whitehouse.gov/briefings-statements/joint-statement-united-states-japan/ (дата обращения: 21.02.2020).

26. U.S.-Japan Trade Agreement Text // Office of the United States Trade Representative. - URL: https://ustr.gov/countries-regions/japan-korea-apec/japan/us-japantrade-agreement-negotiations/us-japan-trade-agreement-text (дата обращения: 11.02.2020).

27. Khlebnikov, S. 6 Key takeaways from The U.S.-Japan trade deal // Forbes. 2019. - October 8. - URL: https://www.forbes.com/sites/sergeiklebnikov/2019/10/08/6key-takeaways-from-the-us-japan-trade-deal/\#4b44d36c690c (дата обращения: 15.02.2020).

28. Bolton, J. The Room where it happened. A White House Memoir/ J. Bolton. [S. 1.] : Simon \& Schuster, 2020. - 570 p.

29. Johnson, J. Trumped by «The Donald»? Bolton book offers peek into Abe's ties with U.S. leader // The Japan Times. - URL: https://www.japantimes.co.jp/news/2020/ 06/23/national/politics-diplomacy/us-donald-trump-john-bolton-book-shinzo-abe/\#.XwJAIB1S $86 \mathrm{~V}(02.07 .2020)$.

\section{References}

1. Torkunov A. Strategiya administratsii Trampa v Aziatsko-Tikhookeanskom regione [Trump's policy in the Asia Pacific region]. Mirovaya ekonomika i mezhdunarodnye otnosheniya, 2019, no. 6, pp. 25-37.

2. Yakovlev P. «Faktor Trampa» i menyayushchiisya oblik globalizatsii [«Trump's factor» and the changing face of globalization]. Mirovaya ekonomika i mezhdunarodnye otnosheniya, 2017, no. 7, pp. 5-14.

3. Schoff J. L. Uncommon Alliance for the Common Good: The United States and Japan After the Cold War. Washington, DC, Carnegie Endowment for International Peace Publications Department, 2017. 272 p.

4. Kelly R. Obama's legacy: leaving Northeast Asia on a high point. The Interpreter, 2017, January 17. Available at: https://www.lowyinstitute.org/the-interpreter/obamaslegacy-leaving-northeast-asia-high-point (accessed 12 January 2020).

5. Garver J.W. China's Quest: The history of the foreign relations of the People's Republic, revised and updated. Oxford: Oxford University Press, 2016. 888 p.

6. Pomfret J. U.S. Concerned about New Japanese Premier Hatoyama. Washington Post. Available at: https:/www.washingtonpost.com/wp-dyn/content/article/2009/12/2 8/AR2009122802271.html?hpid\%3Dtopnews\&sub=AR (accessed 11 January 2020).

7. Goldberg J. How Obama views the men and women who (also) rule the world. The Atlantic. Available at: https://www.theatlantic.com/international/archive/20 16/03/obama-goldberg-world-leaders/473367/ (accessed 12 January 2020).

8. Abiru R. Abe and Obama: a long road. Japan Forward. Available at: https://japan-forward.com/abe-and-obama-a-long-road/ (accessed 13 January 2020). 
9. Chen Yo-Jung. US-Japan relations and Obama's visit to Japan. The Diplomat. Available at: https:/thediplomat.com/2014/04/us-japan-relations-and-obamas-visit-tojapan/ (accessed 12 January 2020).

10. McGregor R. Asia's Reckoning: The struggle for global dominance. Penguin books, 2017. $320 \mathrm{p}$.

11. Backer L. C. The Trans-Pacific partnership: Japan, China, the U.S., and the emerging shape of a new world trade regulatory order. Washington University Global Studies Law Review, 2014, vol. 12, iss.1. Available at: https://openscholarsh ip.wustl.edu/law_globalstudies/vol13/iss1/6/ (accessed 12 January 2020).

12. Joint Press Conference with President Obama and Prime Minister Abe of Japan. The White House, President Barack Obama. Available at: https://obamawhitehouse.ar chives.gov/the-press-office/2014/04/24/joint-press-conference-president-obama-andprime-minister-abe-japan (accessed 13 January 2020).

13. Ford J. The pivot to Asia was Obama's biggest mistake. The Diplomat. Available at: https://thediplomat.com/2017/01/the-pivot-to-asia-was-obamas-biggest-mistake/ (accessed 20 May 2020).

14. Hunt J. Japan's pivot from Obama to Trump. The New Yorker, 2016, December 9. Available at: https://www.newyorker.com/news/news-desk/japans-pivot-from-obamato-trump (accessed 15 February 2020).

15. Lobosco K. Trump pulled out of a massive trade deal. Now 11 countries are going ahead without the US. CNN, 2018, December 30. Available at: https://edition.cn n.com/2018/12/29/politics/tpp-trade-trump/index.html (accessed 16 February 2020).

16. Trump's policy and Japan. Tokyo: NHK, 2017. 231 p.]

17. Smith S. A. Forty-two and counting... The Trump-Abe connection. Council on Foreign Affairs. Available at: https://www.cfr.org/blog/forty-two-and-countingthe-trumpabe-connection (accessed 12 May 2020).

18. Address by Prime Minister Shinzo Abe at the Opening Session of the Sixth Tokyo International Conference on African Development (TICAD VI). Ministry of Foreign Affairs of Japan. Available at: https://www.mofa.go.jp/afr/af2/page4e_000496.html (accessed 21 February 2020).

19. Mehta S. The free and open Indo-Pacific Strategy: a way forward. Asia and the Pacific Policy Society. Available at: https://www.policyforum.net/the-free-and-openindo-pacific-strategy-a-way-forward/ (accessed 23 February 2020).

20. Szechenyi N., Hosoya Y. Working toward free and open Indo-Pacific. Carnegie endowment for international peace. Available at: https://carnegieendowment.org/2019/10 /10/working-toward-free-and-open-indo-pacific-pub-80023 (accessed 12 February 2020).

21. U.S.-Japan joint statement on advancing a free and open Indo-Pacific through energy, infrastructure and digital connectivity cooperation. The White House. Available at: https://www.whitehouse.gov/briefings-statements/u-s-japan-joint-statement-advancing-free- 
open-indo-pacific-energy-infrastructure-digital-connectivity-cooperation/ (accessed 18 February 2020).

22. US President Donald Trump announces revival of QUAD, says working with Pakistan to counter terrorism. Hindustanian Times. Available at: https://www.hindustanti mes.com/india-news/us-president-donald-trump-announces-revival-of-quad-says-working-withpakistan-to-counter-terrorism/story-ZF3R5YRF54a0yJvIKPF6QM.html (accessed 18 February 2020).

23. Terada T. How and why Japan has saved the TPP: From Trump Tower to Davos. The Asan Forum. Available at: http://www.theasanforum.org/how-and-why-japanhas-saved-the-tpp-from-trump-tower-to-davos/ (accessed 17 February 2020).

24. Fujii G. Japan-US allience. Japan's national defense, diplomacy and economy change with Trump. Tokyo, 2017. $208 \mathrm{p}$.

25. Joint Statements of the United States and Japan. The White House. Available at: https://www.whitehouse.gov/briefings-statements/joint-statement-united-states-japan/ (Accessed 21 February 2020).

26. U.S.-Japan trade agreement text. Office of the United States Trade Representative. Available at: https://ustr.gov/countries-regions/japan-korea-apec/japan/us-japantrade-agreement-negotiations/us-japan-trade-agreement-text (accessed 11 February 2020).

27. Khlebnikov S. 6 Key Takeaways from The U.S.-Japan Trade Deal. Forbes, 2019, October 8. Available at: https://www.forbes.com/sites/sergeiklebnikov/2019/10/0 8/6-key-takeaways-from-the-us-japan-trade-deal/\#4b44d36c690c (accessed 15 February 2020).

28. Bolton J. The room where it happened. A White House Memoir. Simon \& Schuster, 2020. $570 \mathrm{p}$.

29. Johnson J. Trumped by «The Donald»? Bolton book offers peek into Abe's ties with U.S. leader. The Japan Times. Available at: https://www.japantimes.co.jp/ne ws/2020/06/23/national/politics-diplomacy/us-donald-trump-john-bolton-book-shinzoabe/\#.XwJAIB1S86V (accessed 2 July 2020). 